\title{
Proceeding
}

Supplementary Issue: Spring Conferences of Sports Science. International Conference on Psychology of Education Sciences \& Lifestyle.

\section{The effect of exercises by using VertiMax device in the development of explosive strength and defensive blocking for handball players}

\author{
HIKMAT ADIL AZIZ AL-LAMI ${ }^{4}$, YOUSIF HUSSEIN ABBAS², HUSSEIN ABDULHADI MAHDI AL- \\ RAHEEM ${ }^{3}$ \\ ${ }^{1}$ Department of Medical Physiology, College of Medicine, University of Al-Qadisiyah, Iraq \\ ${ }^{2}$ The General Directorate of Diwaniyah Education Sport and School Activity Section, Ministry of Education, \\ Iraq \\ 3Ministry of Youth and Sport, Iraq
}

\begin{abstract}
This study aims to prepare special exercises using VertiMax device and to identify the effect of these exercises on the explosive strength and defensive blocking of senior handball players. The researchers have adopted the experimental approach, and the case study is identified by the senior handball players of AlDagharah handball club whose number is 16 , and their lengths ranged $(182.4 \pm 3.282 \mathrm{~cm})$, weights $(82 \pm$ $4.387 \mathrm{~kg}$ ) and ages ( $23 \pm 1.846$ years). They are divided by a simple random method into two groups by (8) players per group in which the experimental group has used exercise by VertiMax device, while the control group has used team coach exercises. The researchers have conducted the explosive strength and defensive blocking tests of the study sample. The training method has included 3 units per week for a period of 6 weeks using the method of high-intensity interval training. The results of the explosive strength and defensive blocking tests have been presented and analysed. It is concluded that the exercises by using the VertiMax as auxiliary and effective devices can be relied upon in developing the explosive strength and defensive blocking of the handball.
\end{abstract}

Keywords: VertiMax; Explosive strength; Defensive blocking; Handball.

\section{Cite this article as:}

Al-Lami, H.A.A., Abbas, Y.H., \& Al-Raheem, H.A.M. (2020). The effect of exercises by using VertiMax device in the development of explosive strength and defensive blocking for handball players. Journal of Human Sport and Exercise, 15(3proc), S966-S972. doi:https://doi.org/10.14198/jhse.2020.15.Proc3.48

Corresponding author. Department of Medical physiology, College of Medicine, University of Al-Qadisiyah, Iraq.

E-mail: alireza.e.amiri@gmail.com

Supplementary Issue: Spring Conferences of Sports Science. International Conference on Psychology of Education Sciences and Lifestyle.

JOURNAL OF HUMAN SPORT \& EXERCISE ISSN 1988-5202

(c) Faculty of Education. University of Alicante

doi:10.14198/jhse.2020.15.Proc3.48 


\section{INTRODUCTION}

If the player reaches the stage of high levels of sports, we find that the training planning is directed to developing the requirements of the game - whether a physical, skilled, planning, psychological ... etc - and working to develop it to the maximum extent so that it can reach the highest sport levels (Kamal et al,1999). During the period of special physical preparation, the process of developing physical characteristics is closely related to the development of motor skills, as the player will not be able to perform optimal basic defensive motor skills in handball unless he has the necessary physical characteristics that require the implementation of these skills with the required accuracy (Dintiman, Ward and Tellez,1998). Special and varied exercises have a great impact in developing the movement of defender by developing the explosive strength of the muscles of the two legs, which in turn works to increase the player's defensive movement speed, as the attention must be paid to the speed of the movements of the legs in order to increase the effectiveness of the defence (Dintiman, Ward and Tellez,1998) and that the increase in the kinematic movement of the legs depends on the development of explosive strength, given that the movements of the legs are one of the basic defensive skills in handball that enable the defender to confront and control the attacker and prevent him from performing the offensive skills with the ball as he possessed it since the defensive movements must be characterized by kinetic speed and explosive strength in steps (Paye,1996; Del, 1993).

The results of some research confirm that the various jumping exercises work to develop the adequacy of the nervous-muscular system for the purpose of performing fast and strong jumps in opposite directions while reducing the performance time of these opposite variables, which gives them an advantage in the jump (Biain, $J$ and Shaiky, 1986). Therefore, the use of exercises by modern devices in handball has a great and important role physically and skilfully in the handball game, and among these devices is VertiMax, which is one of the effective devices in sports training for the handball game, which works to develop the susceptibility of the muscle to contract with a high intensity with contraction with high speed as well, and this is appropriate for the performance of the explosive strength and defensive blocking skill of handball, which needs severe contraction and high speed in contraction, and the explosive strength is one of the most important and necessary physical capabilities for the kinetic performance of handball. It directly affects the speed of movement and the performance of the required skill by the defending player, and for the defending player to be able to block the various shots, with the required strength, speed, and accuracy, he must have physical characteristics such as explosive strength that contribute to the player's performance of defensive duties efficiently throughout the game (Kamal et al,1999).

Hence, the importance of the research was demonstrated by working to develop the explosive strength and the defensive blocking for handball players through the use of modern devices such as VertiMax, which works to use rubber in a regulated manner.

The problem of the study was demonstrated by the researchers' observation that there is a clear weakness in the explosive strength and the defensive blocking, in addition to the lack of using the modern devices and techniques in the training process by the trainers that help to raise the explosive strength of the high-level players in a better and faster way to perform the skill of the defensive blocking, so the researchers saw the use of VertiMax exercises in the development of explosive strength and the defensive blocking of handball players. The aim of the study is to prepare exercises and identify the effect of VertiMax exercises on the development of explosive strength and the defensive blocking of senior handball players. The study hypothesized that there was a positive effect of the VertiMax exercises in developing the explosive strength and defensive blocking of senior handball players. 


\section{MATERIAL AND METHODS}

\section{Design}

The present study adopted the experimental method as it suits with the nature of the problem studied.

\section{Participants}

The study community is identified by the senior handball players of Al- Dagharah Club, with a comprehensive inventory method of $(20)$ players whose lengths ranged $(182.4 \pm 3.282 \mathrm{~cm})$, weights $(82 \pm 4.387 \mathrm{~kg})$ and ages ( $23 \pm 1.846$ years). They were randomly divided into two groups. The first is the experimental group and the second is the control group, after excluding the goalkeepers, the sample has become (16) in which (8) players for each group. The experimental group has used VertiMax exercises, while the control group has used the team coach exercises. Tool: (Stopwatch - Balls - Stand hanging ball- VertiMax.)

\section{Study tests}

Vertical Jump of Stability Test

To measure the explosive strength of the two legs, the player makes a mark with the fingers of the hand on the blocking from the standing position and then swings the arms and bends the torso forward down, and bends the knees then extends the knees and pushes together for the vertical jump to the maximum distance to make a mark on the blocking, the unit of measurement is the distance between the first and second signs (cm) (Muhammad, 2001).

Vertical Jump Test from Motion (Modified)

To measure the explosive strength of the two legs the player makes a mark with the fingers of the hand on the blocking from the standing position and then the player takes a step back, begins taking steps forward and jumping high by marking the blocking, the unit of measurement is the difference between the standing mark and the jumping one from motion $(\mathrm{cm})$.

\section{One-way Defensive Blocking Test}

The player stands on the 6-meter line so that he is facing the ball hanging in the upright on the 9-meter line, he moves forward to jump up by performing the defensive blocking skill in which he touches the suspended ball with both hands, repeating the performance as many times as possible for a period (10s) (Kamal, 2002).

\section{Two-way Defensive Blocking Test}

The player stands on the 6-meter line facing the ball hanging in the upright on the 9-meter line, He moves forward in the direction of one of the two balls to jump up by performing the defensive blocking skill so that he touches the ball suspended with both hands and returns back to back to the 6-meter line to move forward to the direction of the second ball. The player repeats the performance the largest possible number for a period of (15 s) (Kamal, 2002).

\section{Procedures}

- The first day: The explosive strength test was conducted on Saturday 7/9/2019 in the sports hall in Al-Diwaniyah Governorate.

- The second day: The tests of (one-way and - two-way defensive blocking) were conducted for handball on Sunday 9/8/2019.

Exercises using the VertiMax: 
Intensity: from 75-90\%, repetitions: 6-10, sets: 3-4, rest: between repetitions: pulse 120 - $130 \mathrm{~b} / \mathrm{m}$, rest between sets is (2: $4 \mathrm{~m})$, load ripple (2: 1), duration: 6 weeks, units: 3 units per week, 18 training units, highintensity interval training method.

\section{Post-test}

The post-test was conducted on (Saturday - Sunday) corresponding to 26-27 / 10/2019, taking into consideration the same circumstances in which the pre-test was taken.

\section{Statistical Analysis}

The researchers used the SPSS statistic to extract the results of the arithmetic mean, standard deviations, and the coherent and independent $(\mathrm{T})$ value.

\section{RESULTS}

Table 1. Explains the value of $(T)$ and the level of significance $(p)$ is $(<.05)$. The difference is significant between the pre and post-tests and in favour of the post.

Table 1. Explains the arithmetic mean, standard deviations, and the T-value for the results of the explosive.

\begin{tabular}{llllll}
\hline Variables & Experimental group & Mean & SD & T & p \\
\hline \multirow{2}{*}{ Vertical Jump $(\mathrm{cm})$} & Pre-test & 37.75 & 3.28 & 59.32 & .000 \\
& Post-test & 58.93 & 3.20 & 52 & \\
Vertical Jump from motion $(\mathrm{cm})$ & Pre-test & 45.00 & 2.47 & 11.19 & .000 \\
& Post-test & 64.25 & 7.09 & & \\
\multirow{2}{*}{ Blocking by one way $(\mathrm{n})$} & Pre-test & 4.50 & 0.76 & \multirow{2}{*}{11.06} & .000 \\
& Post-test & 8.38 & 0.37 & & \\
Blocking by tow way $(\mathrm{n})$ & Pre-test & 5.50 & 0.53 & \multirow{2}{*}{10.58} & .000 \\
\hline
\end{tabular}

Table 2. It explains the arithmetic mean, standard deviations, and the T-value for the results of the explosive strength tests and the defensive blocking of the control group.

\begin{tabular}{llllll}
\hline Variables & Control group & Mean & SD & T & p \\
\hline \multirow{2}{*}{ Vertical Jump $(\mathrm{cm})$} & Pre-test & 38.13 & 2.90 & 6.07 & .001 \\
Vertical Jump from motion $(\mathrm{cm})$ & Post-test & 48.63 & 3.22 & & \\
& Pre-test & 45.38 & 2.93 & 13.98 & .000 \\
\multirow{2}{*}{ Blocking by one way $(\mathrm{n})$} & Post-test & 53.76 & 4.48 & & \\
& Pre-test & 4.63 & 0.65 & \multirow{2}{*}{10.58} & .000 \\
Blocking by tow way $(\mathrm{n})$ & Post-test & 6.63 & 0.74 & & \\
& Pre-test & 5.63 & 0.52 & \multirow{2}{*}{9.38} & .000 \\
\hline
\end{tabular}

Table 2 explain the value of $T$ and the level of significance $(p)$ is $(<.05)$, the difference is significant between the pre and post-tests and in favour of the post-test.

Table 3 explains the value of $t$ and the level of significance $(p)$ is $(<.05)$. The difference is significant between post-test for the experimental group and control group and in favour of the experimental group. 
Table 3. It explains the arithmetic mean, standard deviations, the value of $t$ for the results of explosive strength tests and the post defensive blocking of the experimental and control group.

\begin{tabular}{llllll}
\hline Variables & Groups & Mean & SD & T & p \\
\hline \multirow{2}{*}{ Vertical Jump $(\mathrm{cm})$} & Experimental group & 58.93 & 3.20 & 6.42 & .000 \\
Vertical Jump from motion $(\mathrm{cm})$ & control group & 48.63 & 3.22 & & \\
\multirow{2}{*}{ Blocking by one way $(\mathrm{n})$} & Experimental group & 64.25 & 7.09 & 3.54 & .000 \\
& control group & 53.76 & 4.48 & & \\
\multirow{2}{*}{ Blocking by tow way $(\mathrm{n})$} & Experimental group & 8.38 & 0.37 & 4.70 & .000 \\
& control group & 6.63 & 0.74 & & \\
& Experimental group & 10.13 & 0.83 & 5.05 & .000 \\
\hline
\end{tabular}

\section{DISCUSSION}

The aim of this study is to prepare special exercises using VertiMax for a period of (6) weeks as a means to develop the explosive strength and defensive blocking of the senior handball players as well as to know the differences between the experimental group and the control group.

All tables explain mathematical means, standard deviations, the T-interconnected and independent value of the explosive strength tests results and the defensive blocking of the senior handball players of Al-Dagharah club for the experimental and control groups.

The results of this study confirm the hypothesis that exercises using VertiMax can promote the development of explosive strength and defensive blocking. As for the differences between the experimental group and the control group, the results were in favour of the experimental group that used the exercises by VertiMax. Previous researchers have studied improving the explosive strength and defensive blocking of handball players, but in this study, it is the first time that has been trained on VertiMax exercises to develop explosive strength and defensive blocking skill for senior handball players.

The data extracted in Table 1 explain the differences in the values of the explosive strength tests and the defensive blocking in the pre and post-tests of the experimental group, as the nature of the sample members showed differences between the two tests in favour of the post-test.

The value of T was (59.32) to test the explosive strength of the stability of the lags, the value of $T$ (11.19) to test the explosive strength of the movement, in the one-way blocking test the value of $T(11.06)$, the value of $T(10.58)$ to test the blocking in two directions, the value of $(p)(<.05)$ for all the above tests, then the difference is significant between the pre and post-tests, and in favour of the post-test for the experimental group. The data extracted in Table (2) explain the differences in the values of the explosive strength tests and the defensive blocking in the pre and post-tests of the control group because the nature of the sample members showed differences between the two tests in favour of the post-test. The value of T (6.07) for testing the explosive strength of the stability of the lags and the value of $T(13.98)$ for testing the explosive strength of the movement, in the one-way blocking test the value of $T$ (10.58), the value of $T(9.38)$ for the test of the blocking in two directions, the value of $(p)(<.05)$ for all the above tests, and then the difference is significant between the pre and post-tests, and in favour of the post-test of the control group. But in the Table 3 explain the differences in the values of the explosive strength tests for the legs (vertical jump from stability - vertical jump from movement) and the skill of the blocking (one-way - two-way) in the dimensional tests of the experimental group, the control group, the nature of the sample members showed differences between the 
two groups and for the benefit of the experimental group. The value of T (6.42) was used to test the explosive strength of the stability of the lags, and the value of $\mathrm{T}$ (3.54) to test the explosive strength of the movement, in the one-way blocking test the value of $\mathrm{T}(4.70)$, the value of $\mathrm{T}(5.05)$ to test the blocking in two directions, and the value $(p)(<.05)$ for all the above tests, then the difference is significant between the pre and posttests, in favour of the post-test for the experimental group. The researchers have attributed the differences between the experimental and control group for the pre and post-tests to use the exercises using the VertiMax device prepared by the researchers. The exercises are characterized by changing in terms of the types of exercises, as well as linking each exercise to the explosive strength with the skill of the defensive blocking. When planning the training program, the coach should focus on the use of special exercises using the VertiMax device that aims to elevate and develop the basic skills of the game and the working muscles during the performance. Explosive strength plays an important role as one of the essential physical characteristics of physical preparation components that characterize handball skills (Adel, 1999), and due to which many factors of superiority and access to higher levels (Kamal and Mohamed, 1980). The explosive strength is also an effective factor in playing handball, and that is why researchers worked to spread suspense through the diversity of exercises using VertiMax device in the training process, as the diversity of exercises and the use of devices in the training process give desire and an excitement in its performance, unlike those that are monotonous, on one pattern and lead to boredom (Antitabine, 2004). Also, the exercises of the VertiMax device are among the effective ways that depend on the organized and coordinated work between the nervous and muscular systems and when the coordination is good between the works of the two devices, the movement becomes consistent and the athlete's ability to perform will be higher (Abul-Ela, 1990).

Here the researchers see that it is necessary for the players to have the explosive power that helps in the defensive wall, which is one of the physical capabilities of the players and that can have a major role in improving their performance as well as giving their teams confidence in order to achieve good results, such as winning games, and this is what the results showed for the experimental group.

As for the results of the explosive strength and defensive blocking, tests were better for the members of the experimental group. By developing the explosive strength of the legs, the skill of the defensive blocking has also developed as VertiMax exercises were mostly related to the muscles of the legs, as they are carried out with a fast and strong kinetic nature and is resistant to fatigue resulting from training. There is a positive relationship between the level of skill of the defensive blocking in handball and the most important special fitness elements in handball which are manifested by explosive strength. Auxiliary devices are important in sports training and their development has also helped in developing the training process because of its live and highly influential experiences in sports training, as the devices help the athlete and the coach in the training process, The addition of training situations with assistive devices that facilitate the training task and encourage responses so that this training affects the competitive or real situation (Yuerib, 2002).

As for the explosive strength and defensive blocking tests of the second control group, we notice a slight development through the adaptations that the player got from the exercises prepared by the coach, as the skill of the blocking depends mainly on the explosive strength. Through what has been presented and discussed for the pre and post-tests of the experimental and control group, the study hypothesis is achieved by finding out a positive effect of the exercise method by using the VertiMax device in developing the explosive strength and defensive blocking of the senior handball players. 


\section{CONCLUSIONS}

The exercises for using the VertiMax contributed to the development of the explosive strength and defensive blocking of the handball players. The preference in development is given to the experimental group which have effectively used VertiMax exercises. The used exercises have achieved the objectives of the research aiming at developing the explosive strength and the defensive blocking of senior handball players.

The coaches must depend on using modern devices and technologies in the training process.

\section{REFERENCES}

Abul-Ela Ahmed Abdel-Fattah.(1990). Athletic Training Physiological Foundations, 1st floor, Cairo, Dar Al-Fikr Al-Arabi, p. 25.

Adel Abdul-Basir.(1999). Mathematical Training and Integration between Theory and Practice, First Edition, Cairo, The Book Center for Publishing, p. 99.

Antitabine. ( 2004). Muscle Building and Strength Training, Cairo, Dar Al-Faruq, p. 32.

Biain, J. shaiky.(1986). coach Guide to Sport Physiology, human training Europe. P.O. Box, w wing leed Leeo, Ts 160-TR. UN, P 74.

Del Harris. (1993). Winning Defense, Master Press, U.S.A, P 65.

Dintiman, ward, Tellez.(1998). Sport Speed, Human Kinetics U.S.A,, P 160 - 161.

Kamal Abdel Hamid and Mohamed Sobhi. (1980).Measurement in Handball, Cairo, Dar Al-Fikr Al-Arabi, p. 53.

Kamal Al-Din Darwish (1999). Defense in Handball, Cairo, The Book Center for Publishing, pp. 161, 152, 215.

Kamal Al-Din Darwish.(2002). Measurement, Evaluation and Analysis of Competition in Handball, Cairo, The Book Center for Publishing, p. 142.

Muhammad Subhi.(2001). Measurement and Evaluation in Physical Education and Sports, part 1, 4th floor, Cairo, Dar Al-Fikr Al-Arabi,, p. 304.

Paye. (1996). Playing The post, Human Kinetics, U.S.A, P 28.

Yuerib Khion. (2002). kinetic learning between principle and application, 1st floor, Baghdad, AI Sakhra Typing Office, p. 185.

\section{(@) $\Theta \Theta \Theta$}

This work is licensed under a Attribution-NonCommercial-NoDerivatives 4.0 International (CC BY-NC-ND 4.0). 